\title{
Empreendedorismo e racionalidade pedagógica moderna: imbricações
}

\author{
Entrepreneurialism and modern pedagogical rationality: imbrications
}

Empreendedorismo y racionalidad pedagógica moderna: imbricaciones

\author{
Claudia Ribeiro CaliXto* \\ JULIO GROPPA AQUINO**
}

\begin{abstract}
RESUMO - Com vistas a uma análise crítica das proposições de uma pedagogia dita empreendedora, o presente artigo tenciona trazer à baila o papel da racionalidade pedagógica moderna na constituição de determinadas formas de governo de si e dos outros, segundo as quais o indivíduo converte-se em capital de si mesmo, e sua própria vida, em ocasião de investimentos formativos ininterruptos. Elegendo Michel Foucault como interlocutor teórico principal, o estudo investiga algumas modulações do poder pastoral e da governamentalidade operadas em textoschave de Pestalozzi, Froebel, Herbart e, em especial, em Os anos de aprendizado, de Wilhelm Meister, romance de formação de Goethe. As reflexões assinalam o fato de que a modernidade pedagógica, em confluência aos preceitos do pietismo, forja um nexo indissociável entre querer, obedecer e empreender, convertendo-se em matriz de certos modos de veridicção/subjetivação correntes.
\end{abstract}

Palavras-chave - Modernidade e educação. Empreendedorismo. Governo. Foucault, Michel.

ABSTRACT - Aiming at a critical review of the proposals of a so called entrepreneurial pedagogy, this article intends to bring up the role played by the rationality of modern pedagogy in the constitution of certain forms of government of self and others, according to which the individual becomes capital of himself, and his own life, occasion for permanent formation investments. Electing Michel Foucault as the main theoretical interlocutor, the study investigates some modulations of pastoral power and governmentality operated in key texts of Pestalozzi, Froebel and Herbart, as well as in Wilhelm Meister's Apprenticeship, novel of formation by Goethe. The reflections point out the fact that pedagogical modernity, in confluence with the precepts of pietism, operates an unbreakable nexus between wanting, obeying and enterprising, becoming a matrix of certain modes of current relations between veridiction/subjectivity.

Keywords - Modernity and education, Entrepreneurialism. Government. Foucault, Michel.

RESUMEN - Con vistas hacia un análisis crítico de las proposiciones de una pedagogía dicha emprendedora, este texto tiene la intención de poner de relieve el papel de la racionalidad pedagógica moderna en la constitución de ciertos modos de gobierno de sí y de los otros, según los cuales el individuo se convierte en capital de sí mismo, y su propia vida, en ocasión de inversiones formativas permanentes. Eligiendo a Michel Foucault como principal interlocutor teórico, el estudio investiga algunas modulaciones del poder pastoral y de la gubernamentalidad manejadas en textos-clave de Pestalozzi, Froebel, Herbart y, en particular, en Los años de aprendizaje de Wilhelm Meister, novela de formación de Goethe. Las reflexiones señalan el hecho de que la modernidad pedagógica, en confluencia con los preceptos del pietismo, forja un vínculo inseparable entre desear, obedecer y emprender, convirtiéndose en matriz de ciertos modos de veridicción/subjetivación actuales.

Palabras clave - Modernidad y educación. Empreendedorismo. Gobierno. Foucault, Michel.

\footnotetext{
*Mestra em Educação pela Universidade de São Paulo (São Paulo, SP, Brasil).E-mail: <claudiacalixto@ig.com.br>.

**Doutor em Psicologia Escolar e do Desenvolvimento Humano pela Universidade de São Paulo (São Paulo, SP, Brasil) e professor na Universidade de São Paulo (São Paulo, SP, Brasil).E-mail: <groppaq@usp.br>.
} 
Já no último quartel do século XX testemunhou-se a emergência do empreendedorismo como um discurso que se alastrou pelo tecido social brasileiro, conquistando amplo espaço nos meios de comunicação, definindo pautas de ação e de convívio entre os cidadãos, bem como orientando políticas educacionais (BRASIL, 2010a, 2010b). Tal discurso adquiriu espessura em meio a um cenário de crise no mundo do trabalho e de acirramento da competitividade (entre nações, empresas e indivíduos), ambos considerados fenômenos inexoráveis da globalização.

A temática do empreendedorismo vem se tornando alvo de investigações no campo das ciências sociais (LÓPEZRUIZ, 2004; GOUVEIA, 2006; BARINI FILHO, 2008; SOUZA, 2009; BARLACH, 2009; MOREIRA, 2011; BOSE, 2013) e, mais esporadicamente, no da educação. (em outros artigos, a palavra "educação" está sendo usada em cxa) Nesse último quadrante, parte dos estudos apregoa o ensino do empreendedorismo como modo de melhoria das condições de vida e de desenvolvimento pessoal (BASTOS, RIBEIRO, 2011; FIGUEIREDONERY, FIGUEIREDO, 2009). Outros, valendo-se de crivos analíticos centrados nos planos da economia e da administração, seja numa perspectiva neomarxista, seja por um mote pós-estruturalista, oferecem análises do empreendedorismo como expressão inequívoca do neoliberalismo (DREWINSKI, 2009; GADELHA, 2010; CARVALHO, 2012; MELO, 2012).

No presente estudo, admite-se a premissa de que o empreendedorismo se constitui como expressão do projeto neoliberal. Este teve sua emergência em meados do século XX, assumindo formas variadas em diferentes territórios. Em Nascimento da biopolítica, Michel Foucault (2008a) destaca as versões alemã e estadunidense do neoliberalismo como formas que marcaram sobremaneira o pensamento político contemporâneo. E compartilharam um contexto de emergência semelhante: "A política keynesiana, os pactos sociais de guerra e o crescimento da administração federal através dos programas econômicos e sociais" (p. 299), produzindo uma crítica contumaz ao intervencionismo econômico estatal.

Ao analisar o neoliberalismo alemão, o pensador francês afirma que, ao se imaginar numa sociedade regulada pelo mercado, "o homo economicus que se quer reconstituir não é o homem da troca, não é o homem consumidor, é o homem da empresa e da produção" (p. 201). Seria, pois, a multiplicação da forma empresa no interior do corpo social que constituiria o escopo da política neoliberal. Já o neoliberalismo estadunidense teria promovido a aplicação de uma grade econômica aos fenômenos tomados até então como somente sociais. Ao tentar reintroduzir o trabalho no campo da análise econômica, trouxe para essa esfera, sob a teoria do capital humano, o que era considerado não econômico. A partir das formulações da Escola de Chicago, temse a decomposição do trabalho em capital e renda, e o homo economicus que aí emerge "é um empresário, e um empresário de si mesmo" (p. 311).

Sem negar as conexões entre economia, administração e domínio educacional, as reflexões do presente artigo pretendem, entretanto, distanciar-se das análises usuais sobre o empreendedorismo, ao eleger como horizonte de problematização o lastro educacionalpedagógico. Este, segundo os autores, parece ter concorrido historicamente para sustentar a constituição de processos de veridicção/subjetivação em torno do homem como construtor de si mesmo. Trata-se, assim, de pôr em causa o papel desempenhado pela racionalidade pedagógica moderna na constituição histórica do empreendedorismo, por meio da análise de um conjunto de textos fundadores da pedagogia no final do século XVIII e início do XIX.

Desta feita, este estudo tem como intercessor privilegiado Michel Foucault, dentre outros pensadores alinhados à perspectiva pós-estruturalista, por meio do emprego das noções de governamentalidade e de pastorado no enfrentamento analítico das fontes eleitas. A primeira noção é formulada por Foucault (2006a) com o fito de descrever o objeto de estudo das artes de governar, o que remete à análise das formas de racionalidade, dos procedimentos, dos cálculos e das táticas que permitem exercer uma modalidade específica de governo da população, por meio da condução das condutas dos próprios cidadãos. Já o pastorado remete a uma forma de governo que se relaciona com a noção de salvação, distendendo uma tecnologia individualizante de ação. Embora o poder pastoral tenha tido seu período áureo, entre os séculos XVI e XVIII, sua tipologia, sua organização e seu modo de funcionamento sobejariam até o presente, agora por meio de uma espécie de inoculação da função pastor pelos próprios sujeitos.

Imbuída de um gesto investigativo de inspiração arqueogenealógica, a investigação levada a cabo centra-se na análise do discurso pedagógico oitocentista, com vistas a perspectivar um horizonte de proveniência/emergência (FOUCAULT, 2005) de um conjunto de questões éticopolíticas caras à atualidade. Dentre elas, a noção da subjetividade como capital e as práticas dela derivadas. Segundo nossa hipótese, o empreendedorismo figuraria como uma potente matriz de governo dos homens na atualidade, instilando narrativas de si que miram a produção de determinados modos de vida, em nome dos quais os indivíduos lançam mão de suas próprias forças (criar, imaginar, conceber, recordar, querer etc.) a fim de se tornarem sujeitos de determinado tipo. 


\section{O EMPREENDEDORISMO COMO MODO DE VIDA}

Tendo em mente os estudos contemporâneos que se dedicaram a tematizar o empreendedorismo, é possível observar a emergência inequívoca da noção de homem como produtor de si mesmo, consubstanciada nas seguintes características desejáveis: iniciativa, visão de futuro e flexibilidade mental; capacidade de assumir riscos; competitividade etc. (LÓPES-RUIZ, 2004; BALL, 2010). Nesse diapasão discursivo, os atributos pessoais, se administrados com eficiência e competência, habilitariam os indivíduos a se sobressaírem num mundo significado como altamente competitivo, bem como a alcançarem o êxito pessoal. Estampa-se, aí, certa laicização da noção de destino, o qual seria fruto do trabalho do próprio homem, resultante da atividade e da atitude laboriosas de si para consigo, tendo em vista o triunfo pessoal e o progresso social (ANDRADE, 2005). Trata-se, enfim, de um destino moldável pelas mãos de cada indivíduo, a reboque da vontade pessoal.

Impregnam o discurso empreendedor as noções de felicidade, salvação e destino, ocupando uma posição central naquilo que se poderia definir como a formação de um regime de vontade que resulta no embate de diferentes forças: o mercado, as demandas sociais e os interesses pessoais. Assim, o plano de verdade que aí se esboça só é tornado possível pelos investimentos massivos sobre a vontade dos indivíduos.

As imagens de liberdade e de autonomia são investidas como certo télos do governo, conquistando lugar estratégico na condução do comportamento do sujeito que empreende a si mesmo. Como analisa Rose (2001), as ideias de liberdade e autonomia que inspiram o pensamento político contemporâneo operam em torno "de uma imagem de ser humano que o vê como o foco psicológico unificado de sua biografia [...] como um ator que busca 'empresariar' sua vida e seu eu por meio de atos de escolha" (p. 164). Consoante a essa razão, investese num sujeito que necessitaria ser flexível, adaptável, dinâmico, inventivo, eficiente e responsável.

Nesse conjunto enunciativo em torno da edificação de si mesmo, desponta o que se costuma designar pedagogia empreendedora (DOLABELA, 2003), a qual teria por finalidade desenvolver atributos individuais relevantes para a produção da felicidade e da salvação pelos próprios cidadãos, num mundo narrado como altamente competitivo e mutável.

Uma noção de velocidade assume posição nodal nesse discurso. A metáfora do gelo fino de Ralph Waldo Emerson, recuperada por Zygmunt Bauman (2010), confere imagem à suposta inevitabilidade de um regime sufocante de tempo, num mundo afirmado como altamente mutável: "Quando se patina em gelo fino, a salvação está na rapidez. Quem quiser se salvar deve se locomover com a velocidade necessária para não correr o risco de forçar demais a resistência de um ponto qualquer" (p. 45). E conclui o autor polonês: "No mundo volátil da modernidade líquida [...], andar é melhor que ficar sentado, correr é melhor que andar, e surfar é ainda melhor que correr. Melhor surfista é o que desliza com leveza e agilidade" (p. 45-46).

Almejando "preparar o profissional do futuro tanto para ser dono do próprio negócio como para atuar como empregado-empregador" (DOLABELA, 2008, p. 12), a pedagogia empreendedora é apontada como uma metodologia inovadora que teria a potência de liberar no indivíduo sua força produtiva.

O conhecimento aí validado é aquele considerado útil em face da instabilidade do mundo da produção de bens e serviços. Daí a necessidade de produzir um homem educável, capaz de aprender a aprender (ANDRADE, 2005; BRASIL 2010b; CORTELLA, 2008; DOLABELA, 2003, 2008). Com efeito, a concepção de pedagogia mobilizada no discurso do empreendedorismo remete a uma maquinaria técnico-pragmática que visaria a acionar e a desenvolver as habilidades e as competências latentes no indivíduo, alterando sua forma de ser e de agir a fim de que fosse possível atingir outro patamar de existência.

Mediante tal horizonte discursivo, que aponta para o empreendedorismo como uma espécie de doutrina ético-política, a investigação em tela operou um recuo metodológico a fim de configurar certos aportes, oriundos do discurso pedagógico, da noção de homem como produtor de seu destino e capital de si mesmo. O que obriga a reconhecê-lo como um discurso vigoroso entre as modalidades de governo dos homens na atualidade.

Para tanto, recorreu-se inicialmente à historiografia da educação com vistas a destacar um jogo de remissivas que indicasse pistas acerca da proveniência de tal noção. Daí serem eleitos textos que se debruçam sobre a história da educação no século XVIII e início do XIX, este reputado como época inaugural da pedagogia contemporânea.

Assim, enveredou-se por um conjunto de obras dedicadas à história da educação e da pedagogia legadas por alguns historiadores no século XX e outros contemporâneos. Dentre elas, destacaram-se: Noções de história da educação, de Afrânio Peixoto (1942); História da educação e da pedagogia, de Lorenço Luzuriaga (1969); História da educação: da antiguidade aos nossos dias, de Mario Alighiero Manacorda (1992); História da pedagogia, de Franco Cambi (1999), dentre outras. Ainda encorparam o conjunto das fontes textos da Coleção Educadores (MEC; FUNDAJ, 2010), produzida pelo Ministério da Educação. 
A incursão em tais obras permitiu que se observasse uma referência recorrente ao século XIX e a seus personagens-chave: Johann Pestalozzi, Friedrich Froebel e Johann Herbart. Contemporâneos entre si, os três pedagogos são referenciados como avatares da pedagogia científica e teriam produzido novas concepções de professor, de ensino e de infância, dispondo, assim, as formas que a escola moderna assumiu (DURÃES, 2011). Daí a opção por tomar suas obras como objeto de análise da presente investigação.

Dentre os textos dos três pensadores, destacam-se: de Pestalozzi, Como Gertrudis enseña a sus hijos (1801/s.d.); de Froebel, A educação do homem (1826/2001) e Pedagogics of the kindergarten (1861/1899); de Herbart, Pedagogia geral (1826/2003). Soma-se a tais textos Os anos de aprendizado de Wilhelm Meister, romance de formação da autoria de Johann Wolfgang von Goethe. A seleção de tal obra, usualmente referenciada como literária, justifica-se na medida em que Goethe, contemporâneo dos três pedagogos, e sua obra em questão espelham fielmente, na visão dos autores deste artigo, a racionalidade pedagógica moderna.

Afiliando-se à perspectiva analítica legada por Michel Foucault, especialmente seus últimos cursos ministrados no Collège de France (FOUCAULT, 2010a; 2010b; 2011), elegeram-se tais textos na busca de assento na perspectiva da história das problematizações. Isto é, o que foi problematizado pelos três pedagogos e por Goethe no contexto sócio-histórico em que viveram é o que constitui o foco do investimento analítico que aqui se envidou, tendo em mente que dali parece provir certos ecos que se fazem presentes naquilo que, hoje, apresenta-se sob o timbre discursivo do empreendedorismo.

\section{O SI COMO PROBLEMA NO DISCURSO PEDAGÓGICO}

Na obra Pedagogia e governamentalidade, ao analisar a emergência da sociedade da aprendizagem na contemporaneidade, Carlos Ernesto Noguera-Ramirez (2011) opera uma incursão arqueogenealógica nos moldes foucaultianos similar à que aqui se pretende realizar, apontando que a Modernidade traz em seu bojo uma indelével marca educativa. Nesse sentido, compreendêla na perspectiva da educação é admitir o processo de constituição de uma sociedade educativa, na qual, segundo esse autor, é possível distinguir três momentos ou formas de ser dos discursos pedagógicos: o momento da instrução (entre os séculos XVII e XVIII), o momento da educação liberal (entre finais do século XVIII e XIX) e, por fim, a sociedade da aprendizagem (do final do século XIX até os dias atuais). Este último momento chama a atenção pela conclamação da aprendizagem permanente e da autoaprendizagem, segundo as quais os próprios indivíduos possuiriam os elementos necessários para definir o que podem e querem aprender (MARÍN-DÍAZ; NOGUERA-RAMÍREZ, 2013).

Este artigo prioriza um recuo ao que o autor denomina educação liberal.

A ciência pedagógica, então nascente em fins do século XVIII, tencionava fundar-se em procedimentos investigativos pautados na observação, na interpretação, na intervenção e no registro de práticas pedagógicas. Pestalozzi, Froebel e Herbart são expoentes dessa iniciativa, na medida em que pretendiam conferir ao saber pedagógico um estatuto de verdade científica.

Para eles, a condução das crianças pautar-se-ia em uma arte psicológica, e o investimento educativo deveria começar desde o nascimento da criança, continuando ao longo da vida. Assim, a racionalidade pedagógica abarcaria o arco temporal de uma existência, tendo fundamentalmente como princípio o equacionamento entre as "individualidades e a multiplicidade" (HERBART, 2003). Observa-se então que o discurso pedagógico moderno buscava estabelecer relações pastorais com as crianças em diferentes domínios: alvejava-se o conjunto da população infantil e cada infante em particular, sob a gestão concomitante das individualidades e da multiplicidade.

Algumas noções têm, para os pedagogos em questão, mobilização estratégica, tal como dispõe Froebel (2001, p.49): "O bem-estar, a felicidade e a salvação do gênero humano". Caberia ao próprio indivíduo sua consecução: "Todos temos meios de alcançá-lo [...] só nós mesmos podemos nos salvar" (p. 50). Segundo o pedagogo, o que tornaria isso possível seria a educação.

$\mathrm{Na}$ produção da maquinaria pedagógica científica do início dos oitocentos, o ambiente tornou-se alvo de especial atenção. Defendia-se a produção de um meio acolhedor e fisicamente estimulante, resguardadas as condições sanitárias, tais como claridade e ventilação. A ambientação física e psicológica tornava-se um dos elementos que convocaria o indivíduo ao exercício de si mesmo.

"Educar-se a si mesmo e educar os outros - com determinação própria, liberdade e consciência - é a dupla ação da sabedoria" (p.23), apregoava Froebel em A educação do homem. Afirmava o pensador, ainda, que a educação emergia como uma exigência humana geral. Para Pestalozzi (s.d.), estarepresentaria uma forma de ação que possibilitaria a cada um fazer-se a si mesmo, constituindo-se uma obra de si por si. O objetivo magno da educação seria a descoberta da vocação da própria vida, o que incluiria um conhecimento íntimo da personalidade do sujeito, de sua verdadeira natureza. 
Entende-se que tais assertivas dão a ver a centralidade, na intervenção pedagógica, da relação consigo mesmo, sendo a descoberta e a narração de si condições para a autonomização do sujeito. Nesse sentido, o próprio homem deveria constituir-se em pedra de toque de si mesmo, por meio de sua interioridade e de sua consciência, tendo como estratégia fundamental a reflexividade (HERBART, 2003).

De Pestalozzi, Froebel e Herbart provém, ainda, a noção de que a educação deve seguir uma ordem evolutiva e acompanhar o progresso das forças do homem. Nesse sentido, visava-se a construir uma ambiência que permitisse às forças naturais do sujeito converteremno em um ser educável. Ademais, a pedagogia deveria assumir flexibilidade, de forma a possibilitar que cada indivíduo encontrasse por si mesmo os caminhos de seu aprendizado. Tal concepção parece articular-se inequivocamente à noção de indivíduo autogovernável: aquele capaz de autoconhecimento, autoaprimoramento e autodesenvolvimento.

No discurso em tela, vê-se emergir a figura do educador (FROEBEL, 2001; PESTALOZZI, s.d.; HERBART, 2003) como personagem e em uma perspectiva diferenciada do que se entendia ser o mestre. Aquele não seria apenas o encarregado da transmissão do conhecimento, mas também quem garantiria um caminho adequado e seguro para se alcançar o fim da educação: a formação do homem.

No entendimento dos autores deste artigo, o educador moderno guardaria semelhanças marcantes com o pastor cristão. Enunciado como figura essencial na condução da instrução do povo, tal como apregoa Herbart (2003), ele deveria, ao mesmo tempo, atentar à individualidade de cada aluno, bem como à fase de desenvolvimento e às características psicológicas individuais.

A educação da vontade é um problema de relevo no discurso pedagógico dos oitocentos, tal como discorre Froebel acerca do conceito de vontade: "É a atividade espiritual do homem, que, de acordo com os fins gerais de sua vida, parte conscientemente de um ponto determinado e vai para uma determinada direção buscar um objeto e fim determinados" (2001, p. 71). A aproximação da vontade de cada um à vontade geral (PESTALOZZI, s.d.) constituiria a vocação da pedagogia. Desta feita, liberar o homem significaria constrangê-lo por meio de um ensino que estimulasse sua vontade livre.

Ainda caberia ao educador promover uma forma de governo autogerida pelos indivíduos, habilitandoos a se dirigirem a um ponto comum, sem dispersão, por livre movimento. Ora, uma economia de governo social de máximas eficiência e eficácia tem como efeito a invisibilização da relação de mando e obediência aí em operação, ao situar o lócus de investimento do poder na vontade e na liberdade pessoais. O método psicopedagógico oitocentista pauta-se, claro está, numa tutela ininterrupta da liberdade.

O discurso pedagógico moderno recodifica a maquinaria do governo teístico que o precede e mobiliza a noção de livre-arbítrio, tal como apregoada por HERBART (2003), de forma a convocar o próprio indivíduo a se governar, sob uma ordem natural que o transcenderia. Entende-se que, por meio de tais operações, efetua-se a formação de um éthos ancorado na modulação de uma razão pastoral na condução das condutas: a salvação torna-se efeito da efetivação de ações do indivíduo no plano terreno. Pelo processo educativo, há de se manifestar "o infinito no finito, o eterno no temporal, o celeste no terreno, o divino no humano e na vida humana" (FROEBEL, 2001, p. 30). Assim, o conceito de salvação circulante remete à ideia de uma realização do homem no mundo terreno, passando a se estabelecer como matéria dos investimentos educativos orientados para a vida prática.

Esse processo parece centrar-se na circulação de racionalidades que orientam o direcionamento das condutas dos indivíduos, por meio das quais se mantêm coesão e coerência a tal ou qual forma de ser, individual e coletivamente. Nessa economia de governo, elaborase, em suma, um equacionamento entre natureza divina, terrena e humana, a reboque da noção de desenvolvimento da humanidade.

A inclusão do trabalho como expressão da essência do homem e força espontânea - um "instinto primitivo de atividade, de produção" (FROEBEL, 2001) - constituiu ocasião fundante para a ascendência de um governo laico. O debate acerca do valor do trabalho no discurso pedagógico dá a ver a modulação do termo como efetivação e melhoria do homem. De fardo a virtude e, então, força criadora, o trabalho passa a compor o plano salvífico crivado pela narrativa cristológica e pela suposta evolução histórica da humanidade, representando o ponto de contato para uma nova plataforma ética.

$\mathrm{Na}$ concepção de homem a vigorar em tal discurso impõe-se certa ambiguidade ao ato educativo: há no homem uma natureza divina e, ao mesmo tempo, terrena, que precisa estar em harmonia. Tal natureza apresentase sempre como uma potência perfectível que nunca se realiza, de modo que o processo educativo converte-se em um trabalho permanente.

É possível afirmar, a partir do que até aqui se desdobrou, que o governo por meio da liberdade representou um problema de destaque para a pedagogia oitocentista. Com vistas à produção de um sujeito educável - o sujeito da pedagogia moderna, por excelência -, o saber pedagógico moderno produz o sujeito do saber, o qual se libertaria de supostas sobredeterminações, a partir da crença de 
que é portador de uma individualidade e de um caminho próprio.

Os textos de Pestalozzi, Froebel e Herbart demonstram que há uma preocupação central com o indivíduo - com suas características, com seu desenvolvimento físico e psicológico -, forjando um investimento discursivo em sua suposta capacidade de autonomia e liberdade. Em suma, o governo de si passa a se constituir, na modernidade pedagógica, em meta do investimento pedagógico.

Ora, como analisa Foucault (2006b), esse foi todo o problema da pastoral católica, reatualizada pela governamentalidade vincada à razão de Estado e que, aqui, efetua uma transmutação no que Sandra Mara Corazza (2005) nomeia pastoral educativa, sob os ares da racionalidade liberal. Como analisara Foucault (2006a), na governamentalidade liberal a liberdade constitui a principal tecnologia de governo dos homens. De parte dos autores deste artigo, é possível admitir que a pedagogia científica contribui decisivamente ao dispor novos movimentos ao jogos de veridicção/subjetivação aí em circulação.

\section{WILHELM MEISTER: NÃO TEMOS NADA SENÃO A NÓS MESMOS}

O romance de Goethe (1796/2009) toma lugar privilegiado no conjunto de fontes da presente investigação, não por uma aproximação ideológica ou temática, mas devido ao jogo de referenciação presente no campo da historiografia da pedagogia. Ou seja, não é a obra em si, mas sua circulação que justifica a convocação. Trata-se da racionalidade ali em movimento, portanto.

No intuito de alcançar uma formação plena e harmônica, o que somente era acessível à aristocracia, o protagonista do romance é movido pela aspiração de desenvolver suas potencialidades. É decisão sua aventurar-se pelo mundo, este convertido em uma escola em que "não é tarefa do aluno terminar alguma coisa, basta que se exercite" (p. 52). De tal encontro, extrair-seiam as experiências de aprendizado importantes para a vida. Seu projeto é conhecer o mundo a fim de conhecer a si mesmo.

A destinação humana é alvo das reflexões do herói mundano. Nesse debate, ganha destaque a ideia de que é necessário domar o destino e contornar as intempéries dos acontecimentos. Necessidade e acaso seriam constituintes da trama do mundo, mas a razão, propriedade natural do homem, possibilitaria seu manejo em favor do próprio indivíduo. Seria trabalho do homem "limitar o arbitrário" (p. 83).

No romance, o projeto de autonomização é cercado pelos temas da razão, da contingência histórica, do destino e da felicidade. Tornar-se útil seria algo basal no processo de formação do indivíduo. Encontrar o que é válido para si e para os outros assume um caráter teleológico no jogo de governo aí em operação. Nesse sentido, a felicidade seria produto da busca de cada indivíduo, estando ao alcance de suas mãos.

$\mathrm{O}$ projeto formativo configura-se, em Meister, como uma maquinaria transformadora do eu e atestável pelo tempo. E o intuito da formação residiria na aliança entre desejos e capacidades, talento e destino. Tratar-se-ia de um empenho pessoal no encontro com as aventuranças e oportunidades da vida, sendo que recobrar a própria vocação seria encargo de sua razão. Esta desvincularia o destino de uma área intangível de vontades alheias ao homem e o aproximaria de uma objetivação, por meio da percepção de "pertencer totalmente a si mesmo" (p.92). O poeta, o artista, seria o homem liberto, o homem autônomo que teria a possibilidade de encontrar o sentido da vida por si próprio.

Desde o início da narrativa, um grupo de nobres da Sociedade da Torre ${ }^{1}$ acompanhava Meister sem que ele o soubesse, enviando pessoas para influenciá-lo em suas decisões e em sua visão de mundo. Seus integrantes conduzem-no ao conhecimento de si e ao desvendamento de suas verdades: a falta de vocação para o teatro, a paternidade desconhecida, os enganos amorosos. As revelações da verdade promovidas pelos membros da Sociedade da Torre ao longo do romance fazem com que o herói mundano efetue imersões profundas sobre si mesmo; o mundo descortina-se como espaço de aprendizado.

A aprendizagem adviria, também, dos equívocos que o indivíduo viesse a cometer na vida, o que dá a ver uma modulação importante no governo dos aprendizes. O destino, alçável às mãos de cada um, admitiria resoluções para a recalcitrância das escolhas no enfrentamento dos percalços da realidade; por meio do erro, poderse-ia aprender algo e daquilo se aprimorar. Tal arranjo lógico afasta o atravessamento trágico das experiências de pensamento dos sujeitos, de forma que o destino assume uma conformação mundana na modulação do ser aprendente como agente. Assim, sob a mediação da Sociedade da Torre, os aprendizes que habitam as páginas de Goethe têm de desenvolver seus talentos e suas habilidades para descobrirem sua interioridade, bem como mediá-la com as necessidades da sociedade em geral. É o sujeito ativo o que se preconiza. Ali não há vitimização, mas aprendizado perene.

Uma ideia que perpassa a obra de Goethe remete à crença de que todo indivíduo, filho da natureza, é passível de aprendizagem, podendo esta se fortalecer mediante aplicação, exercício e estudo. De tal definição emerge uma noção importante à racionalidade pedagógica moderna: a de que o sujeito educável deve ter a capacidade de 
ser maleável, de modo a transformar a própria vida em matéria ética, com vistas ao governo de si.

A educação é esboçada como forma de mediação entre o si e o mundo, ponto de contato entre o querer do sujeito e as constrições da sociedade. No plano educativo, emerge a figura do indivíduo que, interpelado pelo destino, dele tira proveito por meio de sua educação. Ele deve enfrentar os acontecimentos da vida para deles extrair aprendizado, descobrindo e mobilizando suas habilidades e seu talento. Promove-se, assim, o processo de autonomização perante as arbitrariedades do destino e a ação dos educadores. Tal projeto efetiva-se por meio da reflexividade em que o ator-aprendiz encarna o indivíduo que reflete ininterruptamente sobre si e sobre a vida.

Na constituição do homem que procura a si mesmo - o herói mundano -, a noção de talento serviria de salvoconduto para a bela vida, então restrita aos aristocratas. No lugar do berço, o talento. Entende-se ser essa uma noção-chave a determinar a ascese do homem moderno (e contemporâneo): a descoberta e mobilização de seu talento tornaria possível ao indivíduo garantir dado modo de vida, seja este qual fosse, por meios próprios. Tratase da emergência do cidadão (auto)educável que deve, então, investir em seu aprendizado. O indivíduo que não nasceu nobre (condição da herança consanguínea) teria a si mesmo como riqueza, e esse si mesmo poderia dar acesso ao que a natureza melhor lhe ofereceu: "Não temos nada senão a nós mesmos" (p. 214).

Embora se note que a figura do mestre não é suprimida no romance de Goethe, o que chama a atenção em sua obra (e aqui se pode também evocar Werther e Fausto) é a conclamação de um sujeito que passa a assinar sua própria biografia. Há uma espécie de imersão em uma trajetória labiríntica na busca pela aprendizagem, em que a liberdade é norte do exercício de si. No transcorrer dessa jornada, compõe-se uma pauta de julgamento para ajuizar a si e à vida. É o eu que está em questão, portanto.

Os anos de aprendizado de Wilhelm Meister apresentase como expoente de uma conformação de salvação laica: a biografia como fruto de atos de escolha, investimentos subjetivantes, encontros com o conhecimento, edificações de um eu. Parece haver aí uma modulação entre a forma teística cristã, representada pela racionalidade cristã/ protestante, e a pedagogia moderna.

\section{ENCONTRO ENTRE GOVERNAMENTALIDADE E PIETISMO}

O discurso pedagógico do final do século XVIII e início do século XIX movimenta noções que se verificaram caras à contemporaneidade: desenvolvimento, autonomia, liberdade, natureza etc. A série de fontes eleita nesta investigação permitiu perspectivar um plano de dispersão de enunciados que circulararam através dos diferentes textos dos pedagogos analisados e também em Goethe, os quais consubstanciam aportes imanentes à discursividade contemporânea em torno do empreendedorismo.

Esse homem investido por Goethe, tal como em Froebel, Pestalozzi e Herbart, é o ser em pleno desenvolvimento, o qual aprende com as lições da natureza e com a experiência. Seguindo uma espécie de trilha, ele olha para seus rastros, que contribuem - ainda que de maneira imperceptível, diria o escritor alemão para sua formação.

Entre as quatro figuras discursivas eleitas nesta investigação, parece haver uma semelhante lógica em operação: todas elas teceram críticas ao sistema de ensino de seu tempo; suas respectivas teorizações pedagógicas são perpassadas pelas noções de liberdade e autonomia; os quatro autores citados pressupõem um processo de desenvolvimento das capacidades físicas, intelectuais e morais do homem, visando à adequada integração individual e social. Dessa forma, mobilizam em seus discursos determinada concepção de sujeito - a formahomem da Modernidade - mediada por uma relação de cunho essencialmente pedagógico. Como bem apontou Foucault, trata-se de dispor procedimentos para

\begin{abstract}
estender a mão, fazer sair, conduzir para fora. Vemos pois que de modo algum é um trabalho de instrução ou de educação no sentido tradicional do termo, de transmissão de um saber teórico ou de uma habilidade. Mas é uma certa ação, com efeito, que será operada sobre o indivíduo, indivíduo ao qual se estenderá a mão e que se fará sair do estado, do status, do modo de vida, do modo de ser no qual está [..]. É uma espécie de operação que incide sobre o modo de ser do próprio sujeito (2010a, p. 121).
\end{abstract}

Por meio da análise aqui operada, pôde-se notar a constituição de uma crença importante que estabeleceu uma condição de possibilidade para a emergência da subjetividade empreendedora ao final do século XX: a de que seria possível domar o destino por meio da vontade e da mobilização dos próprios talentos. Tal ideia vincula-se a uma política de identidade (PRADO FILHO, 2012), segundo a qual as técnicas de condução do pastorado são incorporadas pelo Estado moderno, operando num jogo de individualização e, ao mesmo tempo, de totalização.

Destarte, o discurso pedagógico moderno produziu formas singulares de governo em que a individualização e o processo de autonomização do sujeito findam por constituir uma retórica contundente acerca do sujeito livre e autônomo, capaz de tomar o destino pelas mãos. Ora, a individualização é uma das características mais marcantes do poder pastoral. Embora a população seja 
considerada o rebanho moderno, a salvação há de ser conquistada principalmente pelo indivíduo, que não mais dependerá intrinsecamente do pastor. Este é inoculado no sujeito, caracterizando aquilo que se entende ser a emergência da função-educador na modernidade. Aqui, supõe-se haver uma modulação da razão pastoral que não se perfaz pela repaginação da figura do velho pastor, mas pela ativação de uma racionalidade governamentalizada que aloca na alma a condição de salvação e nas mãos do próprio indivíduo, o poder e a responsabilidade de sua autotransformação. Tal razão é, ao que tudo indica, axial nas formas de subjetivação alinhadas ao espectro do empreendedorismo contemporâneo.

Tendo em vista o percurso desta análise, realizou-se, por fim, outro recuo temporal, no intuito de se investigar a proveniência da noção de autonomização do homem moderno e sua relação com a lógica pastoral, de modo que se aportou no movimento da Reforma Protestante, significada por Foucault (2008b) como uma batalha pastoral. Deteve-se, em especial, no pietismo, uma vez que se observaram referências renitentes a esse movimento religioso dos seiscentos nas obras e biografias dos autores dos textos analisados anteriormente.

Herdeiro do calvinismo, o pietismo constituiu um modo de equacionamento de importantes forças em embate no século XVII. Dentre elas, as demandas econômicas do comércio e da produção, bem como a emergência das formas absolutistas de gestão estatal sob o ordenamento da razão de Estado, promovendo um ponto de inflexão fundamental para tornar possível a secularização e o modo de salvação laica que se buscou analisar.

Tal como outros movimentos da época, o pietismo trouxe à baila questões problemáticas para o governo da população, a fim de equacionar a relação entre governo de si e governo dos outros, ao efetivar uma espécie de ascese intramundana, como a nomeou Max Weber (2004). Segundo esta, o indivíduo, por meio de uma prática cristã devotada ao labor incessante, investir-se-ia como sujeito predestinado a usufruir a bem-aventurança divina na terra. Uma vida de boas ações e de escolhas responsáveis representava, no pietismo, a credencial para a entrada no reino divino, o qual deveria ser experimentado nos meandros da própria vida cotidiana.

Tal como as demais linhagens protestantes, o pietismo buscou eliminar os artifícios mágicos que povoavam as crenças, cabendo ao sujeito percorrer sozinho a via de sua salvação. Ao lançar luzes para o processo de individualização e autonomização dos indivíduos, propiciou uma recomposição das formas de sentir, de pensar e de se posicionar no mundo, abrindo espaço para o surgimento de novas conformidades subjetivadoras que despontaram a partir do século XVII, dentre as quais se pode destacar o homem que empreende a própria vida.
O principal líder do movimento pietista na Alemanha foi Philip Jacob Spener (1635-1705), ministro luterano influenciado pelos ensinamentos do reformador de origem francesa Jean de Labadie, pelos escritos de Richard Baxter e pela literatura mística de grandes expoentes da Idade Média, como o dominicano Johannes Tauler (13001361) e Meister Eckhart (1260-1327). Spener defendia um caráter mais subjetivo à experiência religiosa.

Sem se separar oficialmente da religião luterana, Spener instituiu a prática de grupos de leitura e de oração em sua casa: as nomeadas collegia pietatis. Tratava-se de reuniões devocionais em que os leigos cristãos se encontravam para trocar experiências e dedicar parte do tempo orando juntos, sem qualquer formalidade ou interferência da tradição da Igreja.

O pietismo representou uma espécie de continuação do luteranismo, porém, com uma diferenciação importante: lançou luzes para o processo de individualização e autonomização dos indivíduos, a reboque de formas mais flexíveis de conduta e do chamamento ao sentimentalismo.

A salvação, segundo Spener, adviria exclusivamente da fé. E a vida piedosa e as boas obras seriam os frutos dela. O princípio da justificação pela graça e pela fé deveria ser encarado como o modus vivendi dos cristãos, sendo que a fé verdadeira seria uma obra divina no homem, que o modificaria e o faria renascer de Deus. A alma individual tornou-se, então, o lugar singular na terra onde Deus e o indivíduo poderiam se fundir em profunda vinculação. Sendo que vida humana e seus feitos constituir-se-iam em uma obra.

Entende-se que foi por meio da noção de obra que a alma se conectou aos problemas econômicos e políticos que emergiam naquela sociedade. Dessa feita, a alma crente, conforme analisa Daniel Tröhler (2008), foi a chave para a solução dos problemas mundanos. A noção de obra e de reavivamento da fé em Deus, por meio do investimento na fé no homem, estabeleceu uma modulação capital no governamento dos viventes, forjando novas relações do homem consigo mesmo, sob a ideia de uma vida interior e de uma prática devotadas ao labor com o objetivo da salvação. E a ascese desse novo cristão implicaria o investimento num trabalho permanente sobre si: a vida como obra, que poderia e deveria ser construída pelo próprio homem. Isso leva a se reconhecer aí a formação precisamente de um éthos, mais do que a conformação de uma forma religiosa, ideológica ou econômica do homem da Modernidade.

O efeito prático dos princípios pietistas, na busca pela salvação humana no interior da vida profissional, conforme analisou Weber (2004), resumiu-se a uma intensificação do controle ascético, aliado a um embasamento religioso da moralidade na profissão ainda "mais firme do que o desenvolvido pela simples 'honestidade' mundana dos 
cristãos calvinistas normais" (p. 119). O pietismo, porém, teria logrado combinar os elementos ascéticos racionais próprios do calvinismo com o desenvolvimento de um sentimento de santidade pessoal em crescente solidez e perfeição. Ambos atrelados à noção de desenvolvimento profissional como o meio ascético por excelência, sendo este a expressão da Providência Divina e a forma privilegiada de expressar a reconciliação e a comunhão com o divino no mundo.

Segundo Weber (2004), os pietistas reuniram virtudes

que podiam pôr em prática, de um lado, o funcionário, o empregado, o operário e o trabalhador que produz em domicílio 'fiéis à sua profissão' e, de outro, empregadores de conformação preponderantemente patriarcal, ostentando sua condescendência a fim de agradar a Deus (2004, p. 126).

A prática do sacerdócio universal, por meio da circulação da palavra, determinou uma importante inflexão no governamento pietista. Todos estariam autorizados a falar a verdade, pautados em seus conhecimentos e dons, uma vez que a esta tiveram acesso direto por meio das Escrituras, tal como está disposto em Pia Desideria, de Philip Jacob Spener, o principal texto do pietismo (BRANDT, 2013).

Foi fundamental a noção de um nascer de novo (ABARCA, 2009) no assentamento da ascese intramundana, dispondo um novo tipo de espiritualidade: alvejava-se um homem renovado, o qual teria a posse de si mesmo pelo acesso direto ao conhecimento de si mesmo. Tratar-se-ia de um processo de deslocamento entre o homem que deixaria de existir em favor de um novo ser: um sujeito que se automelhoraria constantemente, traduzindo seu espírito renovado em feitos e realizações.

Nesse plano, a figura do pastor encontra-se mais difusa. Porém, as noções de salvação, de providência e de glória remanescem nas formas de veridicção em operação, as quais mantêm os sujeitos atados aos modos de subjetivação e objetivação correspondentes. Por meio da racionalidade pietista, aloca-se a vida num sistema de sentido prático. É o limiar do homem que quer, como se pode observar em Meister. O pastorado protestante figura, assim, como o pano de fundo de uma espécie de poder pastoral laicizado que ganhará força e forma indeléveis a partir do século XVIII.

Cabe lembrar, no entanto, que a doutrina da predestinação, herdada do calvinismo e tão cara ao movimento petista, apresenta, aparentemente, uma situação dilemática ao poder pastoral. Se a salvação depende apenas da vontade de Deus e está disposta desde sempre, a relação pastor-ovelha-rebanho tornar-se-ia sem efeito salvífico, descartando-se a economia dos méritos e deméritos do cristianismo católico. Calvino (1998) assim resolve tal imbróglio: "Sabemos que é unicamente Deus quem salva, e que nem mesmo uma ínfima porção de sua glória é transferida para os homens. Mas a glória de Deus não é de forma alguma ofuscada e usa ele o labor humano para outorgar a salvação" (p. 126).

A noção de predestinação produz, então, a intensificação da ascese intramundana, apregoando a ação do próprio homem sobre si, uma vez que, desconhecendo ser um predestinado, ou não, ele necessita envidar esforços para uma vida cada vez mais edificante e laboriosa, como testemunho de fé e da glória de Deus. Não haveria lugar para os indecisos e indolentes.

Erigem-se, assim, as condições de possibilidade de um deslocamento do governamento teístico para uma noção de salvação laica, ancorada na ideia do homem como operador de seu destino. Trata-se de um sujeito capaz de gerir sua vida, imaginando-se construtor de sua própria história, por meio de determinadas práticas pedagógicas sobre si mesmo, tais como voltar o olhar para si, buscar sua motivação e sua verdade supostamente interiores; descobrir e desenvolver seus talentos; aprender a aprender; retirar das experiências com o mundo lições para uma vida bem-sucedida; identificar e aprimorar suas habilidades e aptidões; cuidar da própria saúde, mantendo-se saudável e produtivo.

$\mathrm{Na}$ contemporaneidade, a forma-homem com a qual se defronta, forjada como um rearranjo do poder pastoral no horizonte ético-político do neoliberalismo, entende o sujeito empreendedor como aquele que compõe sua própria empreitada biográfica. Tal fenômeno açula a vontade de uma vida própria e de soluções biográficas particulares, como analisa Stephen Ball (2013). O empreendedor envida esforços para se tornar educável, de modo a permanecer sempre à disposição dos jogos de veridicção/subjetivação em operação.

Destarte, funda-se uma espécie de agenciamento do querer em íntima consonância à racionalidade éticopolítica de cunho neoliberal, lastreada pela produção e pela potencialização de um $e u$ que se empreende vida afora. Entre querer, obedecer e empreender, desenhamse, assim, uma silhueta difusa e um nexo indissociável no que concerne à forja do governo de si e dos outros na atualidade.

\section{REFERÊNCIAS}

ABARCA, Rodrigo. Pietismo: a necessidade de nascer de novo. Uma Revista para Todo Cristão, ano 10, n. 58, ago. 2009. Disponível em: <http://www.aguasvivas.ws/revista/58/ espigando2.htm>. Acesso em: 15 nov. 2013.

ANDRADE, Rosamaria Calaes de(Org.). O empreendedorismo na escola. Porto Alegre: Artmed/Rede Pitágoras, 2005.

BALL, Stephen. Foucault, power and education. New York: Routledge, 2013. 
BALL, Stephen. Performatividades e fabricações na economia educacional: rumo a uma sociedade performativa. Educação \& Realidade, Porto Alegre, v. 35, n. 2, p. 37-55, maio/ago. 2010.

BARINI FILHO, Ulrico. Transmissão da competência empreendedora: um estudo de casos múltiplos. 2008. Tese (Doutorado em Administração) - Faculdade de Economia, Administração e Contabilidade, Universidade de São Paulo, São Paulo, 2008.

BARLACH, Lisete. A criatividade humana sob a ótica do empreendedorismo inovador. 2009. 278 f. Tese (Doutorado em Psicologia) - Instituto de Psicologia, Universidade de São Paulo, São Paulo, 2009.

BASTOS, Maria Flávia; RIBEIRO, Ricardo Ferreira. Educação e empreendedorismo social: um encontro que (trans)forma cidadãos. Revista Diálogo Educacional, Curitiba, v. 11, n. 33, p. 573-594, maio/ago. 2011.

BAUMAN, Zygmunt; MAY, Tim. Capitalismo parasitário: e outros temas contemporâneos. Rio de Janeiro: Jorge Zahar Ed., 2010.

BOSE, Mônica. Empreendedorismo social e promoção do desenvolvimento local. 2013. 182 f. Tese (Doutorado em Administração) - Faculdade de Economia, Administração e Contabilidade, Universidade de São Paulo, São Paulo, 2013.

BRANDT, Darcy Hugo. Phillip Jacob Spener: Pia Desideria. s.d. Disponível em: < http://www.luteranos.com.br/conteudo organizacao/vale-do-itajai/pia-desideria $>$. Acesso em: 15 nov. 2013.

BRASIL. Decreto n ${ }^{\circ} 7.397$, de 22 de dezembro de 2010. Institui a Estratégia Nacional de Educação Financeira. Diário Oficial da União, Brasília, DF, 23 dez. 2010a.

BRASIL. Parecer CNE/CEB no $\underline{\text { 13, de }} 4$ de agosto de 2010. Consulta acerca da inclusão do Empreendedorismo como disciplina no currículo do Ensino Fundamental, do Ensino Médio, da Educação Profissional e da Educação Superior. Diário Oficial da União, Brasília, DF, 6 set. 2010b.

CALVINO, João. As pastorais. São Paulo: Paracletos, 1998.

CARVALHO, Rodrigo Saballa de. Empreendedorismo, autocrítica e flexibilidade: problematizando traços da cultura gestionária de vida nos discursos de pedagogos em formação. Currículo sem Fronteiras, v. 12, n. 2, p. 470-498, maio/ago. 2012.

CORAZZA, Sandra Mara. O jogo do PE: luzes examinantes para o além-mundo da pastoral educativa. Educação e Sociedade, Campinas, v. 26, n. 90, p. 41-75, jan./abr. 2005.

DOLABELA, Fernando. Pedagogia empreendedora: o ensino do empreendedorismo na educação básica, voltado para o desenvolvimento sustentável. São Paulo: Editora de Cultura, 2003.

DOLABELA, Fernando. Oficina do empreendedor. Rio de Janeiro: Sextante, 2008.

DREWINSKI, Jane Maria de Abreu. Empreendedorismo: o discurso pedagógico no contexto do agravamento do desemprego juvenil. 2009. 157 f. Tese (Doutorado em Educação) - Setor de Educação, Universidade Federal do Paraná, Curitiba, 2009.

DURÃES, Sarah Jane Alves. Aprendendo a ser professor(a) no século XIX: algumas influências de Pestalozzi, Froebel e Herbart. Educação e Pesquisa, São Paulo, v. 37, n. 3, p. 465-480, set./dez. 2011.
FIGUEIREDO-NERY, Maria Auxiliadora Negreiros de; FIGUEIREDO, Paulo. Práticas pedagógicas lúdicas: fontes iniciais para mentes criativas e empreendedoras? Revista Educação em Questão, Natal, v. 35, n. 21, p. 27-52, maio/ ago. 2009.

FOUCAULT, Michel. Nietzsche, a genealogia, a história. In: FOUCAULT, Michel. Arqueologia das ciências e história dos sistemas de pensamento. Rio de Janeiro: Forense Universitária, 2005. p. 260-281 (Ditos e escritos II).

FOUCAULT, Michel. A governamentalidade. In: FOUCAULT, Michel. Estratégia, poder-saber. 2. ed. Rio de Janeiro: Forense Universitária, 2006a. p. 281-305 (Ditos e escritos IV).

FOUCAULT, Michel. "Omnes et singulatim": uma crítica da razão política. In: FOUCAULT, Michel. Estratégia, podersaber. 2. ed. Rio de Janeiro: Forense Universitária, 2006b. p. 355-385 (Ditos e escritos IV)

FOUCAULT, Michel. Nascimento da biopolítica: curso dado no Collège de France (1978-1979). São Paulo: Martins Fontes, 2008a.

FOUCAULT, Michel. Segurança, território, população: curso dado no Collège de France (1977-1978). São Paulo: Martins Fontes, 2008b.

FOUCAULT, Michel. A hermenêutica do sujeito: curso no Collège de France (1981-1982). 3. ed. São Paulo: WMF Martins Fontes, 2010a.

FOUCAULT, Michel. O governo de si e dos outros: curso no Collège de France (1982-1983). São Paulo: WMF Martins Fontes, 2010b.

FOUCAULT, Michel. A coragem da verdade: curso no Collège de France (1983-1984). São Paulo: WMF Martins Fontes, 2011.

FROEBEL, Friedrich. Pedagogics of the kindergarten, or his ideas concerning the play and playthings of the child. New York: D. Appleton and Company, 1899.

FROEBEL, Friedrich. A educação do homem. Passo Fundo: UPF Editora, 2001.

GOETHE, Johann Wolfgang Von. Os anos de aprendizado de Wilhelm Meister. São Paulo: Ed. 34, 2009.

GOUVEIA, Tatiana Bittencourt. A demanda empreendedora e o trabalho imaterial na construção da subjetividade do "empreendedor". 2006. 157 f. Dissertação (Mestrado em Administração) - Escola de Administração, Universidade Federal do Rio Grande do Sul, Porto Alegre, 2006

HERBART, Johann. Pedagogia geral: a multiplicidade do interesse (livro segundo). Lisboa: Fundação Calouste Gulbenkian, 2003.

LÓPEZ-RUIZ, Osvaldo Javier. O éthos dos executivos das transnacionais e o espírito do capitalismo. 2004. Tese (Doutorado em Ciências Sociais) - Instituto de Filosofia e Ciências Humanas, Universidade Estadual de Campinas, Campinas, 2004.

MARÍN-DÍAZ, Dora Lilia; NOGUERA-RAMIREZ, Carlos Ernesto. El arte de governar moderno: o de la constitución de una ciência de la educación. Educação, Porto Alegre, v. 36, n. 2, p. 156-167, maio/ago. 2013. 
MEC; FUNDAJ. Coleção Educadores. Disponível em: <http:// www.dominiopublico.gov.br/pesquisa/ResultadoPesquisa ObraForm.do? first $=50 \&$ skip $=0 \& d s \_$titulo $=\&$ co_autor $=\&$ no_autor $=\&$ co_categoria $=133 \&$ pagina $=1 \&$ select_action $=$ 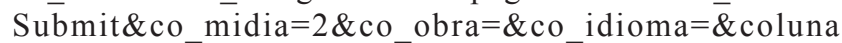 Ordenar $=$ DS_-TITULO\&ordem $=$ null $>$. Acesso em: 10 fev. 2011.

MELO, Alessandro de. A educação básica na proposta da Confederação Nacional da Indústria nos anos 2000. Educação e Pesquisa, São Paulo, v. 38, n. 1, p. 29-45, 2012. http://dx.doi. org/10.1590/S1517-97022011005000003.

MOREIRA, Rita. Empreendedorismo na Universidade do Minho: o caso dos diplomados das ciências sociais. Publicações eletrônicas seriadas do Centro de Investigação em Ciências Sociais da Universidade do Minho, out. 2011.

NOGUERA-RAMIREZ, Carlos. Pedagogia e governamentalidade ou da Modernidade como uma sociedade educativa. Belo Horizonte: Autêntica, 2011.

PESTALOZZI, Johann. Como Gertrudis enseña a sus hijos. 2. ed. Mexico: Ensayos Pedagogicos, s.d.a.

PRADO FILHO, Kleber. A política das identidades como pastorado contemporâneo. In: CANDIOTO, César; SOUZA, Pedro de (Org.). Foucault e o cristianismo. Belo Horizonte: Autêntica, 2012. p. 111-120.

ROSE, Nikolas. Inventando nossos eus. In: SILVA, Tomaz Tadeu da (Org.). Nunca fomos humanos: nos rastros do sujeito. Belo Horizonte: Autêntica, 2001. p. 137-204.
SOËTARD, Michel. Johann Pestalozzi. GASPARIN, João Luís; MARCONDES, Martha Aparecida Santana. (Org.). Recife: Fundação Joaquim Nabuco, Ed. Massangana, 2010.

SOUZA, Maria Cristina de Andrade. Crescimento econômico, inovação e empreendedorismo. 2009. 154 f. Dissertação (Mestrado profissional em Economia) - Faculdade de Ciências Econômicas, Universidade Federal do Rio Grande do Sul, Porto Alegre, 2009.

TRÖHLER, Daniel. The educationalization of the modern world: progress, passion, and the protestant promise of education. In: SMEYERS, Paul; DEPAEPE, Marc. (Ed.). Educational research 3: the educacionalization of social problems. New York: Springer, 2008. p. 31-46.

UNESCO. Towards an entrepreneurial culture for the twenty-first century: stimulating entrepreneurial spirit through entrepreneurship education in secondary schools. Geneva: International Labor Organization and United Nations Educational, Scientific and Cultural Organization, 2006.

WEBER, Max. A ética protestante e o "espírito" do capitalismo. São Paulo: Companhia das Letras, 2004.

\section{NoTA}

1 Trata-se de uma sociedade secreta formada por um grupo de nobres com o
fim de ajudar vários jovens a alcançarem o desenvolvimento e a formação
que eles almejam.

Artigo recebido em abril 2014.

Aprovado em julho 2015. 